Check for updates

Cite this: RSC Adv., 2018, 8, 35131

Received 2nd September 2018 Accepted 28th September 2018

DOI: $10.1039 / c 8 r a 07323 f$

rsc.li/rsc-advances

\section{Morphology engineering of nickel molybdate hydrate nanoarray for electrocatalytic overall water splitting: from nanorod to nanosheet $\uparrow$}

\author{
Jianghao Wang, ${ }^{\text {ab }}$ Liping Li, ${ }^{c}$ Lingshen Meng, ${ }^{c}$ Liping Wang, ${ }^{c}$ Yifeng Liu, ${ }^{c}$ Wenwen Li, ${ }^{c}$ \\ Wengang Sun ${ }^{\mathrm{C}}$ and Guangshe Li (D) *ac
}

\section{Introduction}

There is an emergent need for the development of new clean energy technologies, especially those based on water splitting, to meet the ever-increasing power demand in our daily life. ${ }^{1,2}$ Much attention is focused on the design of advanced electrocatalysts for water splitting. Some commercial noble metalbased nanomaterials, such as $\mathrm{Pt} / \mathrm{C}, \mathrm{IrO}_{2}$ and $\mathrm{RuO}_{2}$, exhibit low overpotential, small Tafel slope, and high exchange current density, but are still facing severe bottleneck problems including rare resources, high price, and poor electrochemical stability as well as their single performance. ${ }^{3-6}$ Hence, developing inexpensive and efficient catalysts as alternatives to Ptbased materials for hydrogen evolution reaction (HER) and $\mathrm{IrO}_{2}$ for oxygen evolution reaction (OER) is a crucial step for boosting widespread application of water splitting in the energy conversion process. ${ }^{7,8}$

\footnotetext{
${ }^{a}$ Key Laboratory of Design and Assembly of Functional Nanostructures, Fujian Institute of Research on the Structure of Matter, Chinese Academy of Sciences, Fuzhou 350002, P. R. China. E-mail: guangshe@jlu.edu.cn

${ }^{b}$ University of Chinese Academy of Sciences, Beijing 100049, P. R. China

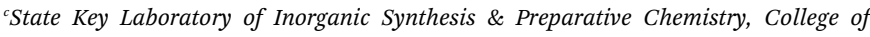
Chemistry, Jilin University, Changchun 130012, P. R. China

$\dagger$ Electronic supplementary information (ESI) available. See DOI: $10.1039 / \mathrm{c} 8 \mathrm{ra} 07323 \mathrm{f}$
}

Nanoarrays grown on a substrate exhibit great potential for water splitting due to the following advantages: (i) nanoarray can be directly used as a working electrode for water splitting without the aid of polymer binders, which is beneficial for exposing active sites promoting electrolyte penetration; (ii) nanoarray has a strong interaction with the conductive substrate, which facilitates electron transportation; ${ }^{9,10}$ (iii) nanoarray structure is propitious to the superaerophilic ability of electrode, and thus release $\mathrm{H}_{2}$ or $\mathrm{O}_{2}$ easier during water splitting. ${ }^{11-13}$ Fascinated by the merits of nanoarray, various nanoarrays, such as nanorod, nanosheet, and hierarchical structure have been synthesized successfully by precise chemical methods. But, it is still hard to realize the morphology change of nanoarray selectively by a simple optimization. The syntheses of these nanoarrays generally involve complicate optimizations of reaction conditions including surfactant, $\mathrm{pH}$, and dissolvent, which damage their further application. ${ }^{14-17}$ Therefore, it is an emergency to develop a new simple method to modulate the morphology of nanoarray.

To this end, we take $\mathrm{NiMoO}_{4} \cdot \mathrm{H}_{2} \mathrm{O}$ as an example, the modulation of nanoarray morphology from nanorod to nanosheet is realized by simply changing the hydrothermal temperature without the aids of surfactants or additives. We can obtain nanorod array when hydrothermal temperature below or equal to $150^{\circ} \mathrm{C}$. While the hydrothermal temperature is as high as $180^{\circ} \mathrm{C}$, the array on $\mathrm{Ni}$ foam is nanosheet instead of nanorod. 
In addition, the performance of $\mathrm{NiMoO}_{4} \cdot \mathrm{H}_{2} \mathrm{O}$ nanorod array as bifunctional catalysts toward overall water splitting depends highly on the hydrothermal temperature in the sample preparation. When hydrothermal temperature equals to $150{ }^{\circ} \mathrm{C}$, the obtained sample shows a superior OER and HER activity performance separately, affording a large current density of 10 $\mathrm{mA} \mathrm{cm} \mathrm{cm}^{-2}$ at an overpotential of $<240$ and $200 \mathrm{mV}$ toward oxygen evolution reaction and hydrogen evolution reaction, respectively. As expected, the electrolyzer using $\mathrm{NiMoO}_{4} \cdot \mathrm{H}_{2} \mathrm{O}$ nanorod array as both anode and cathode for catalyzing overall water splitting exhibited the great performance, obtaining a current density of $10 \mathrm{~mA} \mathrm{~cm}^{-2}$ at $1.67 \mathrm{~V}$, comparable to the integration of commercial noble-metal $\mathrm{Pt} / \mathrm{C}$ and $\mathrm{IrO}_{2}$ electrodes.

\section{Experimental section}

\section{Materials}

All reagents were purchased from commercial sources and used as received without further purification. Potassium hydroxide $(\mathrm{KOH})$, Nickel nitrate hexahydrate $\left(\mathrm{Ni}\left(\mathrm{NO}_{3}\right)_{2} \cdot 6 \mathrm{H}_{2} \mathrm{O}\right)$, sodium molybdate dihydrate $\left(\mathrm{Na}_{2} \mathrm{MoO}_{4} \cdot 2 \mathrm{H}_{2} \mathrm{O}\right), \mathrm{Pt} / \mathrm{C}(20 \mathrm{wt} \%), \mathrm{IrO}_{2}$ were purchased from Sinopharm Chemical Reagent Co. Ltd. (Beijing, China). All aqueous solution was prepared using ultrapure water (>18 M $\Omega$ ).

\section{Synthesis of $\mathrm{NiMoO}_{4} / \mathrm{NF}$}

To remove the surface nickel oxide, Ni foam $(2 \mathrm{~cm} \times 3 \mathrm{~cm})$ was ultrasonically cleaned by acetone and $\mathrm{HCl}$ solution ( $3 \mathrm{M}$ ) for $15 \mathrm{~min}$ in turn and subsequently rinsed with water and ethanol for three times. The cleaned Ni foam was immersed into $60 \mathrm{~mL}$ of a solution that contains $3 \mathrm{mmol} \mathrm{Ni}\left(\mathrm{NO}_{3}\right)_{2} \cdot 6 \mathrm{H}_{2} \mathrm{O}$ and $3 \mathrm{mmol}$ $\mathrm{Na}_{2} \mathrm{MoO}_{4} \cdot 2 \mathrm{H}_{2} \mathrm{O}$ in a Teflon-lined stainless autoclave $(100 \mathrm{~mL})$. The solution $\mathrm{pH}$ at which hydrothermal treatment is about 6.47. Then the autoclave was sealed and treated in an oven at $150{ }^{\circ} \mathrm{C}$ for $6 \mathrm{~h}$. The resultant sample was washed with ethanol three times and finally dried at $60{ }^{\circ} \mathrm{C}$ for $2 \mathrm{~h}$. To study the effect of temperature on the formation of $\mathrm{NiMoO}_{4}$ nanorod array, the similar processes were performed in different reaction temperature $\left(120{ }^{\circ} \mathrm{C}, 180{ }^{\circ} \mathrm{C}\right)$. For convenience, the products were marked as NMO- $T$ ( $T$ is the hydrothermal temperature).

To investigate the growth mechanisms of nickel molybdate hydrate nanoarray, we did some control experiments including the Ni-salt precursor, hydrothermal time, conductivity substrate, and concentration of Ni-salt precursor. Detailed experimental conditions are shown in Table S1. $\dagger$

\section{Characterization and instrumentations}

Phase structures of the samples were characterized by powder X-ray diffraction (XRD) $(\mathrm{Cu} \mathrm{K} \alpha, \lambda=1.5418 \AA$ A) on a Rigaku Miniflex apparatus. Raman spectrum was recorded for powder sample in the backward geometry on Labram HR800 Evolution using the excitation wavelength of $532 \mathrm{~nm}$ from a He-Ne laser at room temperature. Scanning electron microscopy (SEM) performed on JSM-6700F and transmission electron microscopy (TEM) on F20 were used to study the morphologies of the samples. X-ray photoelectron spectroscopy (XPS) measurements were achieved using an ESCALAB 250Xi spectrometer (Thermo Fischer Scientific) equipped with an $\mathrm{Al} \mathrm{K} \alpha$ monochromatic source. The charging shift was calibrated the $\mathrm{C} 1 \mathrm{~s}$ photoemission line at a binding energy of $284.8 \mathrm{eV}$.

\section{Electrochemical characterization}

All electrochemical measurements were carried out on a CHI 760E electrochemical analyzer (CHI Instruments, Inc., Shanghai) in a standard three-electrode system. In this work, the potentials were displayed versus RHE by the RHE calibration: $E(\mathrm{RHE})=E(\mathrm{Hg} / \mathrm{HgO})+0.098+0.0591 \times \mathrm{pH}$. Linear scan voltammetry (LSV) was measured with a scan rate of $5 \mathrm{mV} \mathrm{s}^{-1}$ and all results were revised by the ohmic potential drop $(i R)$ correction. Cyclic voltammetry (CV) measurements with different scan rates $\left(40,80,120,160,200 \mathrm{mV} \mathrm{s}^{-1}\right)$ were used to determine the electrochemical double layer capacitances (EDLC, $C_{\mathrm{dl}}$ ). The electrochemical impedance spectroscopy (EIS) measurements were carried out at an overpotential of $370 \mathrm{mV}$ in the frequency range of $10^{-2}$ to $10^{5} \mathrm{~Hz}$. Prior to all the above measurements, oxygen was bubbled into the electrolyte for $30 \mathrm{~min}$.

For the comparative purpose, the different control materials in powdered forms $\left(\mathrm{Pt} / \mathrm{C}, \mathrm{IrO}_{2}\right)$ were drop-casted on $\mathrm{Ni}$ foam. Their amount and working surface area were kept the same as those used for NMO-150. In typical procedure: (1) $7 \mathrm{mg}$ of catalyst was dispersed in $1 \mathrm{~mL}$ mixture of $450 \mu \mathrm{L}$ de-ionized water, $500 \mu \mathrm{L}$ ethanol and $50 \mu \mathrm{L} 5 \%$ Nafion to form a homogeneous mixture, (2) $500 \mu \mathrm{L}$ of this solution was drop-casted onto $\mathrm{Ni}$ foam electrode with an area of $1 \mathrm{~cm}^{2}$ and a loading amount of $3.5 \mathrm{mg} \mathrm{cm}^{-2}$, and left to dry in air.

\section{Results and discussions}

The $\mathrm{NiMoO}_{4} \cdot \mathrm{H}_{2} \mathrm{O}$ nanorods and nanosheets were directly grown on commercial Ni foam by a hydrothermal method, as schematically elucidated in Fig. 1A. The cleaned Ni foam was immersed into a mixed solution of nickel nitrate and sodium molybdate $(60 \mathrm{~mL})$ in a Teflon-lined stainless autoclave. Then the autoclave was sealed and reacted at a selected temperature for $6 \mathrm{~h}$. Fig. 1B illustrates optical pictures of the primitive $\mathrm{Ni}$ foam and sample NMO-150. The color of Ni foam is changed from silver to yellow after the hydrothermal reaction, indicating that the active materials are uniformly coated on the Ni foam.

To optimize the synthetic temperature of the growth of nanoarray, we adjusted the reaction temperature from $120^{\circ} \mathrm{C}$ to $180{ }^{\circ} \mathrm{C}$. The phase structures of $\mathrm{NiMoO}_{4} \cdot \mathrm{H}_{2} \mathrm{O}$ nanoarrays were characterized by X-ray diffraction (XRD, Fig. 2). As shown in Fig. 2, the nanoarrays prepared under 120,150 , and $180^{\circ} \mathrm{C}$ have a similar XRD pattern. In addition, the diffraction peak of XRD pattern in Fig. 2 agrees well with the data for $\mathrm{NiMoO}_{4} \cdot \mathrm{H}_{2} \mathrm{O}$ (JCPDS no. 13-0128), revealing that all nanoarrays grown on $\mathrm{Ni}$ substrate are $\mathrm{NiMoO}_{4} \cdot \mathrm{H}_{2} \mathrm{O} .{ }^{18}$ In addition, Raman spectroscopy is used to monitor the structure of NMO-150. As shown in Fig. $S 1, \dagger$ a set of Raman peaks are observed at 805, 831, and $938 \mathrm{~cm}^{-1}$, which are in consistent with previously reported $\mathrm{Mo}-$ 
A

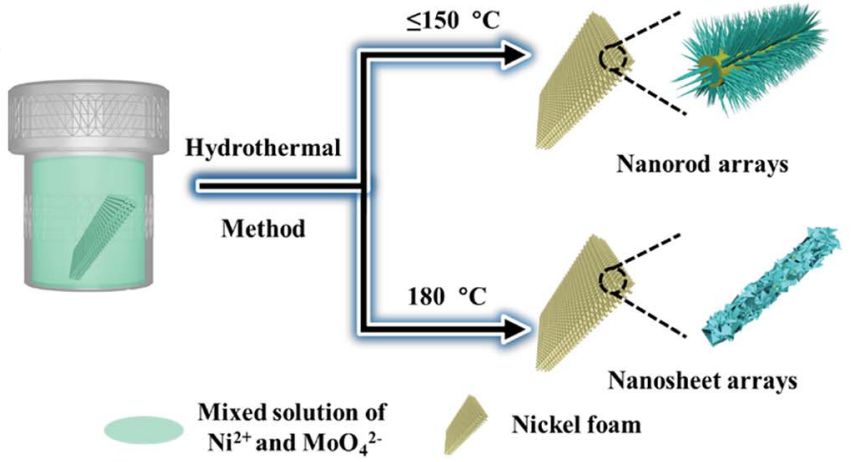

B

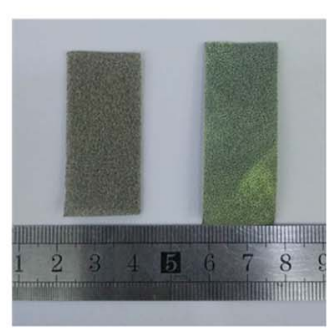

Fig. 1 (A) Schematic illustration of the preparation process for $\mathrm{NiMoO}_{4}$ hydrate array and (B) photography of the bare Ni foam (left) and NMO150 (right).

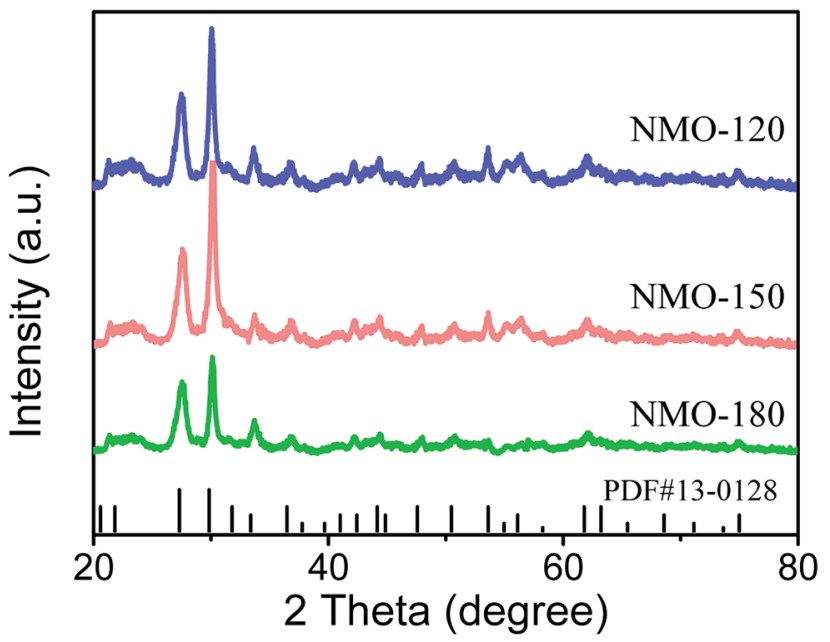

Fig. 2 XRD patterns for NMO-120, NMO-150, NMO-180. The data were recorded for the powder that was scraped from Ni foam.

O vibrations of $\mathrm{NiMoO}_{4} \cdot{ }^{19}$ The Raman spectrum also demonstrates the existence of $\mathrm{NiMoO}_{4} \cdot \mathrm{H}_{2} \mathrm{O}$ in the sample.

Fig. 3 shows the scanning electron microscopy (SEM) images of NMO-120, NMO-150, and NMO-180. The low-magnification SEM images in the left panel (Fig. 3(A, C, and E)) reveal that all samples are covered by a rough shell, indicating the successful growth of $\mathrm{NiMoO}_{4} \cdot \mathrm{H}_{2} \mathrm{O}$ nanoarrays. The highmagnification SEM images shown in Fig. 2(B and D) demonstrate that the nanorods are covered on $\mathrm{Ni}$ foam for the samples that were obtained at the hydrothermal temperature of $120^{\circ} \mathrm{C}$ or $150{ }^{\circ} \mathrm{C}$. Comparatively, when the hydrothermal temperature is as high as $180^{\circ} \mathrm{C}$, the array on $\mathrm{Ni}$ foam is nanosheet instead of nanorod (Fig. 2F). This interesting finding demonstrates that hydrothermal temperature is an important parameter for the growth of nanoarrays. Different morphology of nanoarray from nanorod to nanosheet can be obtained by simply changing the hydrothermal temperature without the aid of surfactants or additives. The effect of temperature on the growth of nanoarrays is changing the Ni source that reacts with $\mathrm{MoO}_{4}{ }^{2-}$ ions from $\mathrm{Ni}^{2+}$ ions to $\mathrm{Ni}$ foam. When the reaction temperature below or equal to $150{ }^{\circ} \mathrm{C}, \mathrm{MoO}_{4}{ }^{2-}$ ions react with $\mathrm{Ni}^{2+}$ ions in the solution, and then $\mathrm{NiMoO}_{4} \cdot \mathrm{H}_{2} \mathrm{O}$ nanorods grow on the $\mathrm{Ni}$ foam directly. While reaction temperature equal to $180{ }^{\circ} \mathrm{C}, \mathrm{MoO}_{4}{ }^{2-}$ ions react with $\mathrm{Ni}$ foam directly to form nanosheet array, ${ }^{20,21}$ which impedes the growth of $\mathrm{NiMoO}_{4} \cdot \mathrm{H}_{2} \mathrm{O}$ nanorod. To verify this suppose, some control experiments were performed (Table $\mathrm{S} 1 \dagger)$. Firstly, we changed the Ni-precursor by $\mathrm{NiCl}_{2} \cdot 6 \mathrm{H}_{2} \mathrm{O}$ and $\mathrm{NiSO}_{4} \cdot 6 \mathrm{H}_{2} \mathrm{O}$. From Fig. S2, $\dagger$ we find that nanorod array can still be obtained under similar reaction conditions when using $\mathrm{NiCl}_{2} \cdot 6 \mathrm{H}_{2} \mathrm{O}$ and $\mathrm{NiSO}_{4} \cdot 6 \mathrm{H}_{2} \mathrm{O}$ as Ni-salt precursor, which demonstrate that the change in Ni-precursor has little effect on the morphological evolution. Secondly, we have replaced $\mathrm{Ni}$ foam with carbon cloth under the $180^{\circ} \mathrm{C}$ for $6 \mathrm{~h}$. As shown in Fig. S3, $\dagger$ we find that nanorod instead of nanosheet array can be obtained, providing the evidence of that the $\mathrm{Ni}^{2+}$ ions of NMO180 are origin from Ni foam. Thirdly, we have changed the concentrations of Ni-salt $(0,6 \mathrm{mmol})$ to investigate the contribution of $\mathrm{Ni}^{2+}$ ions. From Fig. $\mathrm{S} 4, \dagger$ one can find that when the concentration of Ni-salt was $0 \mathrm{mmol}$, only the nanosheet array can be obtained, indicating that when $\mathrm{Ni}^{2+}$ ions come from the $\mathrm{Ni}$ foam, the dimensional anisotropy would be changed from 1D to $2 \mathrm{D}$. When the concentration of Ni-salt was $6 \mathrm{mmol}$, only the nanorod array can be obtained, suggesting that additional contribution of $\mathrm{Ni}^{2+}$ ions would not result in the sheet-like structure.

NMO-120, NMO-150, NMO-180 were prepared under different hydrothermal temperature, which might result in a different activity for water splitting. To verify this suppose, the catalytic tests of oxygen evolution reaction (OER) and hydrogen evolution reaction (HER) for these three samples were performed in $1 \mathrm{M} \mathrm{KOH}$ electrolyte (Fig. S5 and S6 ${ }^{\dagger}$ ). As shown in (Fig. S5 and S6†), the sample of NMO-150 exhibits superior catalytic performance both in the OER and HER processes than other samples. This is because of the following two reasons. On the one side, the thickness of $\mathrm{NiMoO}_{4}$ films over $\mathrm{Ni}$ foam varied with hydrothermal temperature. From Fig. S5, † we can find that the oxidation peak of $\mathrm{Ni}^{2+} / \mathrm{Ni}^{3+}$ become weak with the increase of hydrothermal temperature, suggesting that the thickness of $\mathrm{NiMoO}_{4}$ films also become thinner. The nanosheet grown on the Ni foam would impede the growth of $\mathrm{NiMoO}_{4} \cdot \mathrm{H}_{2} \mathrm{O}$ nanorod and decrease the amount of active species on the Ni substrate. Therefore, NMO-180 may have a less activity than NMO-150. On the other side, although nanorods covered $\mathrm{Ni}$ foam were 

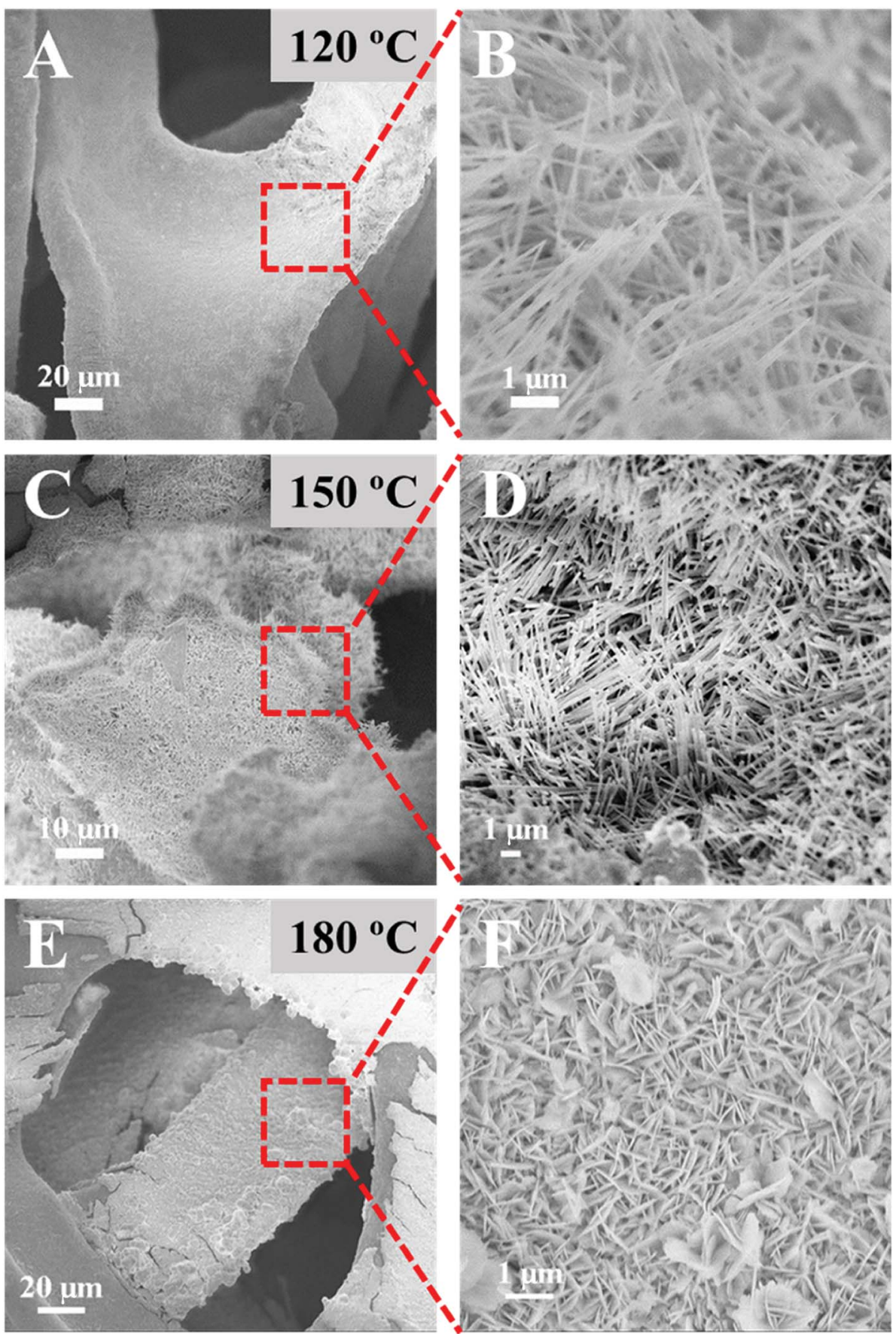

Fig. 3 Low-magnification (left panel) and high-magnification (right panel) SEM images of NMO-T samples synthesized at the hydrothermal temperature of $120^{\circ} \mathrm{C}(\mathrm{A}$ and $\mathrm{B}), 150^{\circ} \mathrm{C}(\mathrm{C}$ and $\mathrm{D})$ and $180^{\circ} \mathrm{C}(\mathrm{E}$ and $\mathrm{F})$.

prepared at both $120^{\circ} \mathrm{C}$ and $150{ }^{\circ} \mathrm{C}$, higher temperature $\left(150{ }^{\circ} \mathrm{C}\right)$ could enhance the synergistic effect between $\mathrm{NiMoO}_{4}$ and $\mathrm{Ni}$ foam, which is beneficial to catalysis. Hence, the reaction temperature of $150{ }^{\circ} \mathrm{C}$ is the optimum condition for the growth of $\mathrm{NiMoO}_{4} \cdot \mathrm{H}_{2} \mathrm{O}$ nanorod array, and thus NMO-150 is picked to systemically study its physical properties and catalytic performances.

To study the effect of hydrothermal time on the growth of nanorod array, we controlled the hydrothermal time ( $2 \mathrm{~h}, 4 \mathrm{~h}$ ) under similar condition. From Fig. S7, $\uparrow$ we can find that the samples treated by the hydrothermal method for $2 \mathrm{~h}$ and $4 \mathrm{~h}$ have a rod-like structure. With the increase of hydrothermal time, the length of nanorod become longer, which demonstrate that the growth mechanism of nickel molybdate hydrate nanoarray obeys the orientation attachment growth. Transmission electronic microscope (TEM) was performed to further reveal the morphology of NMO-150. As shown in Fig. 4A, the nanorod with a size about $150 \mathrm{~nm}$ in diameter can be clearly seen, which is consistent with the observation of SEM. Moreover, a large number of mesopores can be found easily on the 

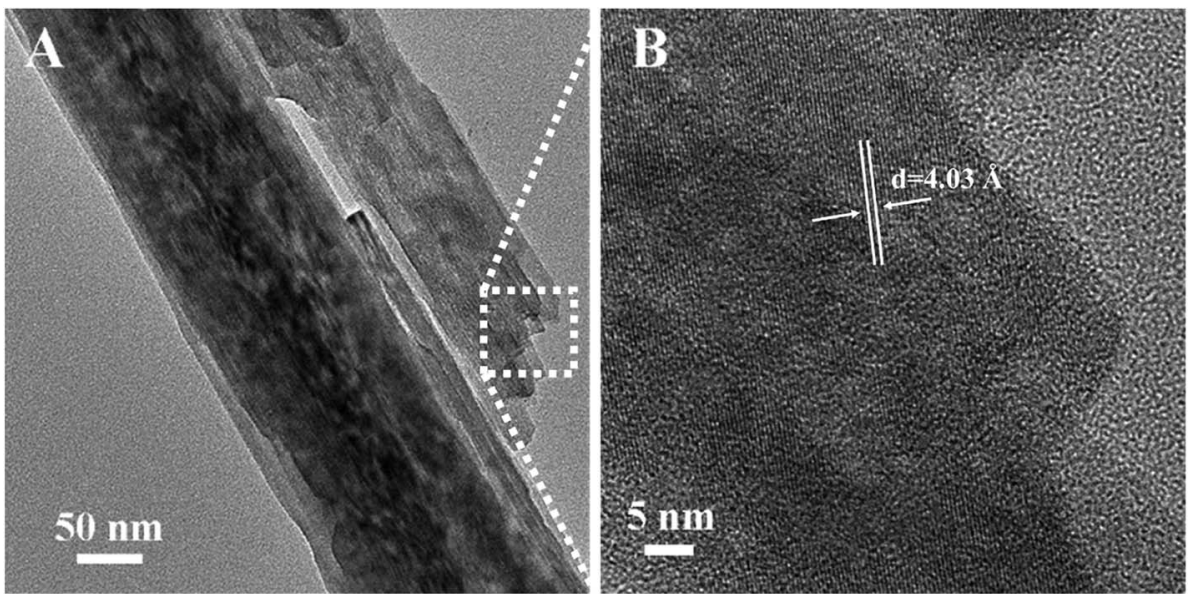

Fig. 4 TEM (A) and HRTEM (B) of NMO-150. The powder for the TEM was scraped from Ni foam.

surface of the nanorod. Measurements of isothermal $(77 \mathrm{~K}) \mathrm{N}_{2}$ adsorption and desorption for NMO-150 were performed to characterize the surface area and porosity of the product (Fig. S8 $\dagger$ ). The average pore diameter of the NMO-150 is about 3-5 $\mathrm{nm}$ to the desorption data (Fig. $\mathrm{S} 8 \dagger$ ). The existence of the mesoporous structure can not only increase the surface area of the catalyst but also provide more defects to produce an excellent catalytic performance. The corresponding high-resolution TEM (Fig. 4B) shows that the spacing between two adjacent lattice fringes is $4.03 \AA$.

The detailed surface chemical feature of NMO-150 was further determined by X-ray photoelectron spectroscopy (XPS). The XPS survey spectrum (Fig. 5A) shows typical signals of Ni, Mo, O elements, consistent with EDS analysis (Fig. S9†). In the Mo 3d core-level spectrum (Fig. 5A), two peaks at 232.2 and
$235.3 \mathrm{eV}$ are attributed to Mo $3 \mathrm{~d}_{5 / 2}$ and Mo $3 \mathrm{~d}_{3 / 2}$ respectively, and the spin-orbital splitting is about $3.0 \mathrm{eV}(\Delta \mathrm{Mo} 3 \mathrm{~d}$ ). The values for the binding energy of Mo $3 \mathrm{~d}_{5 / 2}$ and $\Delta$ Mo $3 \mathrm{~d}$ are the typical features of the $\mathrm{Mo}^{6+}$ ion, ${ }^{22}$ which suggests that valence state of Mo ions in NMO-150 is +6 . The Ni 3p in Fig. $5 \mathrm{C}$ exhibits a complicate spectrum comparing to pure $\mathrm{Ni}^{2+}$ and metal nickel. ${ }^{21}$ In addition to the strong photoelectron peaks at 856.3 and $874.2 \mathrm{eV}$ and two satellite peaks at high binding energy side, two peaks at low binding energy are also distinguished. Therefore, the Ni 2 p spectrum was de-convoluted into two spinorbit doublets. The strong doublet at binding energies of 856.3 and $874.2 \mathrm{eV}$ is ascribed to $\mathrm{Ni}^{2+}$, while the other one at 852.3 and $869.3 \mathrm{eV}$ is assigned to $\mathrm{Ni}^{0}$ that comes from $\mathrm{Ni}$ foam. ${ }^{23}$ The $\mathrm{O} 1 \mathrm{~s}$ signals with binding energies of $530.7 \mathrm{eV}$ and $532.7 \mathrm{eV}$ correspond to oxygen species in lattice and hydrate, respectively. ${ }^{3,24}$
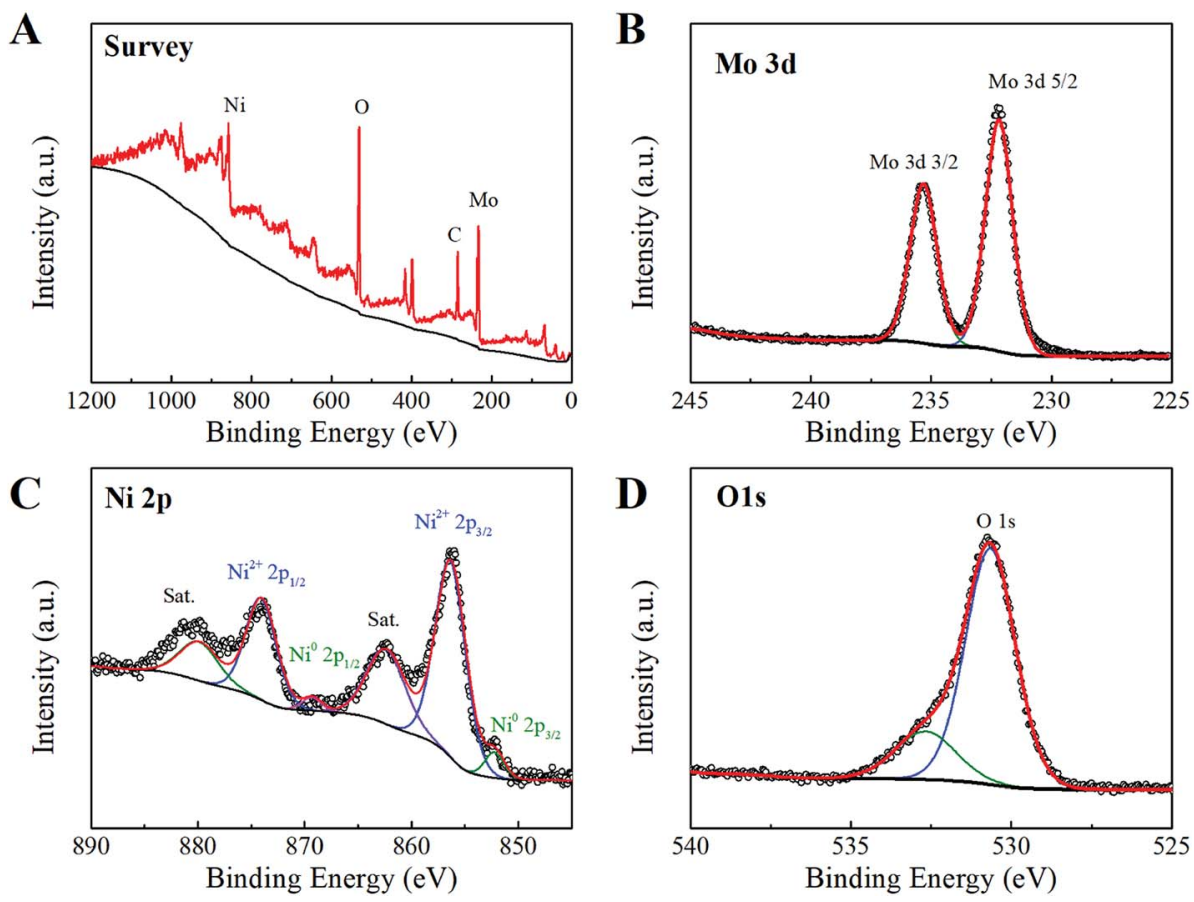

Fig. 5 X-ray photoelectron spectrum of $\mathrm{NiMoO}_{4} \cdot \mathrm{H}_{2} \mathrm{O}$ : (A) survey spectrum, (B) Mo 3d, (C) Ni $2 \mathrm{p}$ and (D) O $1 \mathrm{~s}$. 

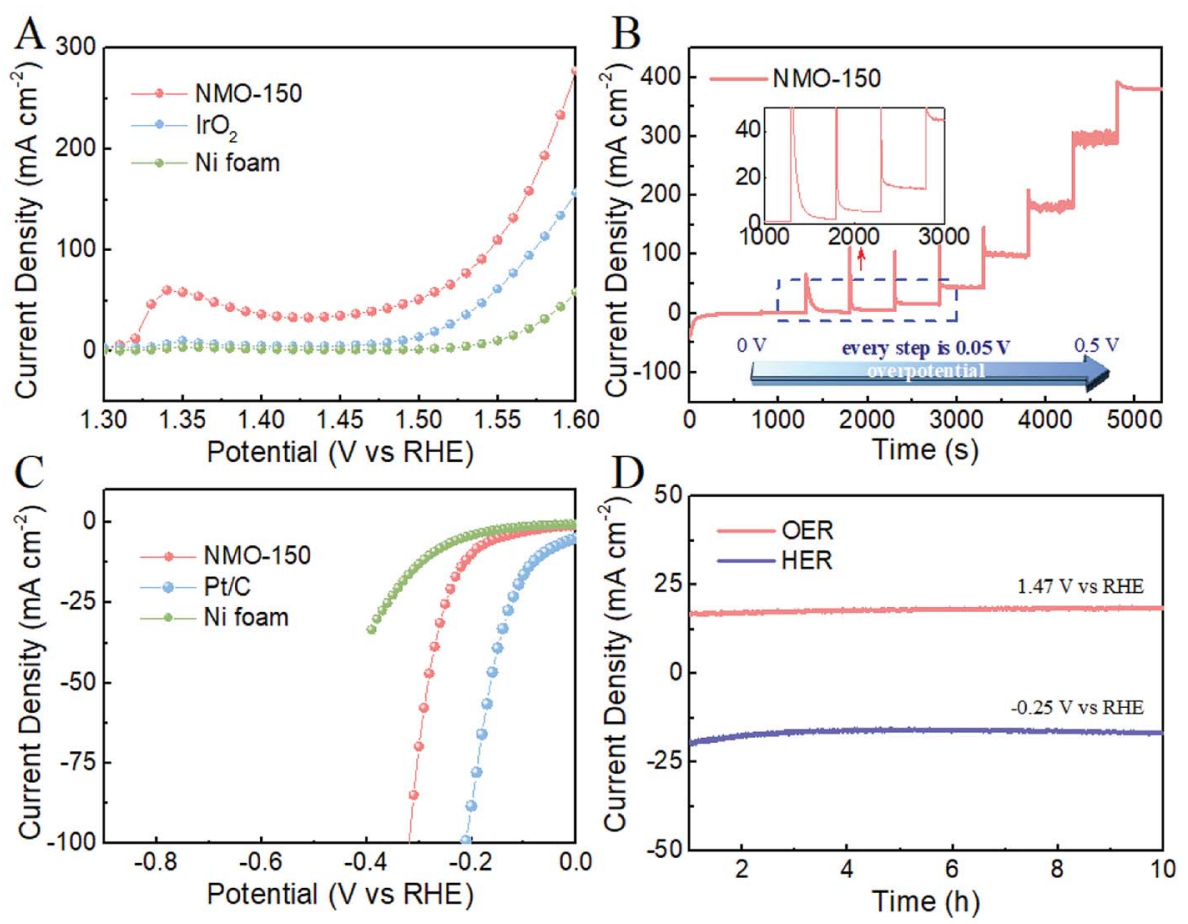

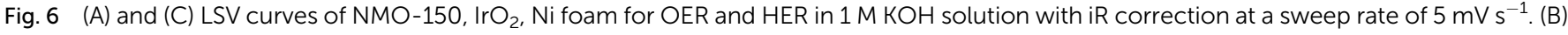
The multi-step chronoamperometric curve obtained with NMO-150 in $1 \mathrm{M} \mathrm{KOH}$ solution, measured at different overpotentials, starting at $1.23 \mathrm{~V}$ and ending at $1.73 \mathrm{~V}$ (vs. RHE) with an increment of $50 \mathrm{mV}$ every $500 \mathrm{~s}$. (D) Current density versus time (I-t) curve obtained over NMO-150 at $1.47 \mathrm{~V}$ and $-0.25 \mathrm{~V}$ (vs. RHE) over $10 \mathrm{~h}$ long electrocatalytic OER and HER.
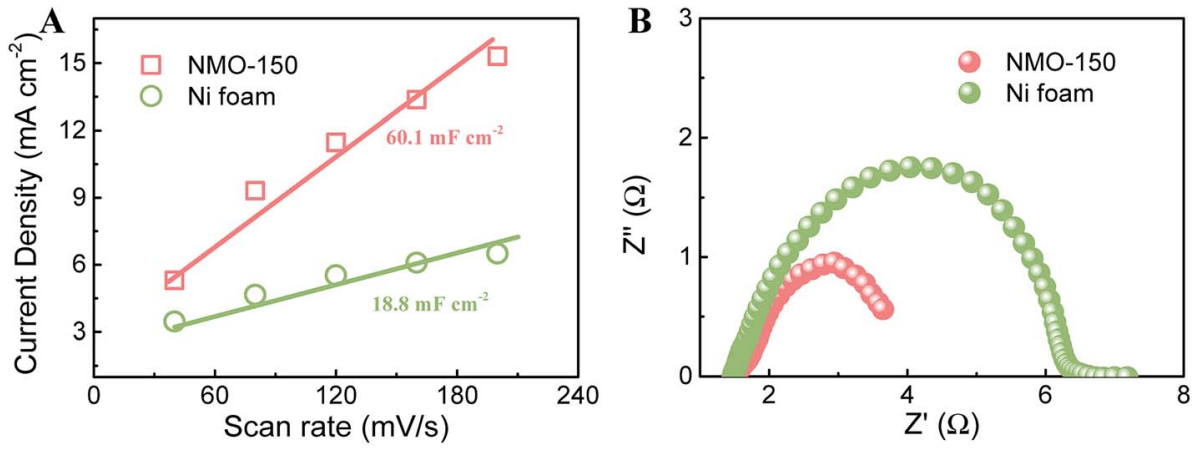

Fig. 7 (A) Relationship between current density and scan rate, and (B) EIS Nyquist plots recorded at an overpotential of $270 \mathrm{mV}$ for NMO-150 and $\mathrm{Ni}$ foam.

According to the above XPS results, it can be concluded that the valences of $\mathrm{Ni}, \mathrm{Mo}$, and $\mathrm{O}$ elements are $+2,+6$, and -2 , respectively. These observations indicate that $\mathrm{NiMoO}_{4}$ hydrate nanorod array has been synthesized successfully through a convenient hydrothermal method.

We evaluated the electrocatalytic activity of NMO-150 for OER and HER in $1 \mathrm{M} \mathrm{KOH}$ solution by a typical three-electrode system, in which NMO-150 was tailored into $1 \times 1 \mathrm{~cm}^{2}$ and directly used as the working electrode. For comparison, we also measured the electrocatalytic activity of $\mathrm{Ni}$ foam, Ni foamsupported of commercial $\mathrm{IrO}_{2}$. As shown in Fig. 6A, NMO-150 shows a remarkable catalytic activity toward OER, with a current density of $\approx 280 \mathrm{~mA} \mathrm{~cm}{ }^{-2}$ at a small overpotential of $370 \mathrm{mV}$, which is superior to many electrocatalysts reported previously. ${ }^{20,25-28}$ Moreover, the activity of NMO-150 is apparently better than that of $\mathrm{IrO}_{2}$, the benchmark for OER. Specifically, NMO-150 achieves a current density of 100, 150, $200 \mathrm{~mA}$ $\mathrm{cm}^{-2}$ with small overpotentials of about $310,330,350 \mathrm{mV}$, respectively. Where to reach the current density of 100 and 150 $\mathrm{mA} \mathrm{cm}{ }^{-2}$, the $\mathrm{IrO}_{2}$ must be applied larger overpotentials of 340 and $370 \mathrm{mV}$, respectively. Furthermore, at an overpotential of

Table 1 Resistances and capacities derived from EIS fitting according to the circuit shown in Fig. $7 \mathrm{C}$

\begin{tabular}{llllll}
\hline Samples & $R_{\mathrm{S}}(\Omega)$ & $R_{\mathrm{ct}, 1}(\Omega)$ & $\mathrm{CPE}_{1}-\mathrm{p}$ & $R_{\mathrm{ct}, 2}(\Omega)$ & $\mathrm{CPE}_{2}-\mathrm{p}$ \\
\hline NMO-150 & 1.48 & 0.55 & 0.44 & 1.89 & 0.94 \\
Ni foam & 1.36 & 0.19 & 0.77 & 3.03 & 0.72
\end{tabular}



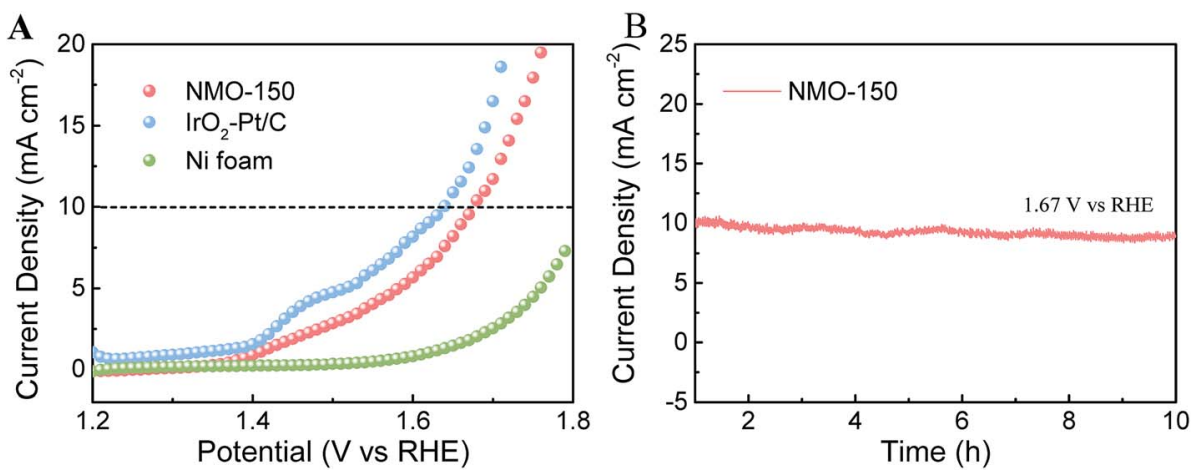

Fig. 8 (A) Comparison of LSV curves detected for three electrolyzers containing NMO-150-NMO-150, Pt/C-IrO 2 and Ni foam-Ni foam couple, respectively, for overall water splitting with $i R$ correction at a scan rate of $5 \mathrm{mV} \mathrm{s}^{-1}$. (B) The chronoamperometric curve of water electrolysis for NMO-150 in a two-electrode configuration at a static potential of $1.67 \mathrm{~V}$.

$370 \mathrm{mV}$, the current density of NMO-150 is about two and six times larger than commercial $\mathrm{IrO}_{2}$ and $\mathrm{Ni}$ foam. These results confirm the excellent OER performance of NMO-150.

Fig. 6B shows a multi-step chronoamperometric curve of NMO-150 toward OER in $1 \mathrm{M} \mathrm{KOH}$ solution. The operated overpotential was applied starting at $1.23 \mathrm{~V}$ and ending at $1.73 \mathrm{~V}$ (vs. RHE) with an increment of $50 \mathrm{mV}$ every $500 \mathrm{~s}$. The current maintains stable at each potential in the whole range, from 50 to $550 \mathrm{mV}$, and the current also switch quite rapidly, suggesting that NMO-150 has an excellent stability in a wide current density range $\left(0-400 \mathrm{~mA} \mathrm{~cm} \mathrm{~cm}^{-2}\right)$ and good mass transport property. $^{29}$

We also examined the catalytic property of NMO-150 toward HER in basic media. For comparison, the electrocatalytic activity of $\mathrm{Ni}$ foam and $\mathrm{Ni}$ foam-supported of commercial $\mathrm{Pt} / \mathrm{C}$ (20 wt\%) were measured under the same testing condition. As shown in Fig. 6C, although the activity of NMO-150 is lower than that of $\mathrm{Pt} / \mathrm{C}$ (20 wt\%), much higher than that of Ni foam. When overpotential is $0.3 \mathrm{~V}$, the current density for NMO-150 is about $75 \mathrm{~mA} \mathrm{~cm}^{-2}$, which is nearly seven times larger than Ni foam. To evaluate the stability of NMO-150, current density-time $(I-t)$ curves for OER and HER in $1 \mathrm{M} \mathrm{KOH}$ were recorded at the potential of $1.47 \mathrm{~V}$ and $-0.25 \mathrm{~V}$ ( $v s$. RHE). As shown in Fig. 6D, NMO-150 retains the current density at $15 \mathrm{~mA} \mathrm{~cm}^{-2}$ over as long as $10 \mathrm{~h}$ electrocatalytic OER and HER. This further demonstrates that NMO-150 is a highly stable electrocatalyst for both OER and HER in basic media.

The electrochemical double layer capacitances (EDLC) were measured to evaluate the active area of electrocatalysts. Fig. 7A compares the variation of current density with scan rate for NMO-150 and Ni foam. Their double-layer capacitance $\left(C_{\mathrm{di}}\right)$ values can be calculated by the slopes. ${ }^{3,30,31}$ The value of $C_{\mathrm{dl}}$ for NMO-150 is $60.1 \mathrm{mF} \mathrm{cm}^{-2}$, about three times larger than $\mathrm{Ni}$ foam, indicating that NMO-150 possesses a larger active area among all samples studied. Electrochemical impedance spectroscopy (EIS) for NMO-150 and Ni foam was recorded in $1 \mathrm{M}$ $\mathrm{KOH}$ solution at an overpotential of $270 \mathrm{mV}$ to determine their electrical conductivity. The equivalent circuit is shown in Fig. S10. $\uparrow$ As illustrated in Fig. 7B and Table 1, comparing to Ni foam, sample NMO-150 exhibits smaller $R_{\mathrm{ct}, 2}$ (charge transfer resistance) and. The smaller $R_{\mathrm{ct}, 2}$ suggests that the charge transfer in the NMO-150 is more fluent, which could give a higher reaction rate. ${ }^{32-34}$ Therefore, the excellent catalytic activity of NMO-150 can attribute to a large number of active sites and improved electrical conductivity.

Given our finding that NMO-150 has an exotic bi-functional property toward OER and HER, we assembled an electrolyzer with NMO-150 as anode and cathode to study its activity for overall water splitting (OWS). As illustrated in Fig. 8A, the electrolyzer using NMO-150 as anode and cathode affords current density of $10 \mathrm{~mA}^{-2}$ at $1.67 \mathrm{~V}$ (vs. RHE). Despite this current density value is slightly inferior to that of electrolyzer constructed by $\mathrm{Pt} / \mathrm{C}-\mathrm{IrO}_{2}$ couple, it outperforms state-of-the-art electrolyzers utilizing Co- or Ni-based bifunctional electrocatalysts for overall water splitting. ${ }^{34}$ Furthermore, the longterm stability of this system was also tested. When the static potential of $1.67 \mathrm{~V}$ was applied, the electrolyzer afforded a constant current density around $10 \mathrm{~mA} \mathrm{~cm} \mathrm{~cm}^{-2}$ and showed an excellent stability after testing for $10 \mathrm{~h}$ (Fig. 8B).

\section{Conclusion}

In summary, $\mathrm{NiMoO}_{4} \cdot \mathrm{H}_{2} \mathrm{O}$ nanorod and nanosheet arrays are prepared by a simple one-pot hydrothermal method. We can realize the morphological change of array from nanorod to nanosheet by only tuning the hydrothermal temperature without the aids of surfactants or additives. Nanorod array can be obtained when hydrothermal temperature below or equal to $150{ }^{\circ} \mathrm{C}$. While the hydrothermal temperature is as high as $180^{\circ} \mathrm{C}$, the array on $\mathrm{Ni}$ foam is nanosheet instead of nanorod. Electrochemical tests showed that the nanorod array synthesized at $150{ }^{\circ} \mathrm{C}$ possesses remarkable catalytic activity toward both OER and HER. NiMoO${ }_{4} \cdot \mathrm{H}_{2} \mathrm{O}$ nanorod array afforded current density of $10 \mathrm{~mA} \mathrm{~cm} \mathrm{~cm}^{-2}$ for OER and HER at small overpotentials of $<240 \mathrm{mV}$ and $200 \mathrm{mV}$, respectively. Furthermore, the electrolyzer with $\mathrm{NiMoO}_{4} \cdot \mathrm{H}_{2} \mathrm{O}$ nanorod array as electrocatalyst at both sides of the electrodes also exhibited high performance for the overall water splitting reaction. In consideration of its excellent catalytic activity and the facile and scalable synthesis, $\mathrm{NiMoO}_{4}$ hydrate nanorod array might hold great promise as a substitutable non-noble metal-based electrode material towards large-scale electrical water splitting. 


\section{Conflicts of interest}

The authors declare no competing financial interest.

\section{Acknowledgements}

This work was financially supported by NSFC (Grants 21571176, 21611530688, 21771171, 21671077 and 21025104).

\section{References}

1 Z. W. Seh, J. Kibsgaard, C. F. Dickens, I. Chorkendorff, J. K. Nørskov and T. F. Jaramillo, Science, 2017, 355, eaad4998.

2 Y. Zhu, X. Ji, R. Yin, Z. Hu, X. Qiu, Z. Wu and Y. Liu, RSC Adv., 2017, 7, 11123-11128.

3 J. Wang, L. Li, H. Tian, Y. Zhang, X. Che and G. Li, ACS Appl. Mater. Interfaces, 2017, 9, 7100-7107.

4 M. Q. Yu, L. X. Jiang and H. G. Yang, Chem. Commun., 2015, 51, 14361-14364.

5 B. Zhang, X. Zheng, O. Voznyy, R. Comin, M. Bajdich, M. García-Melchor, L. Han, J. Xu, M. Liu, L. Zheng, F. P. García de Arquer, C. T. Dinh, F. Fan, M. Yuan, E. Yassitepe, N. Chen, T. Regier, P. Liu, Y. Li, P. De Luna, A. Janmohamed, H. L. Xin, H. Yang, A. Vojvodic and E. H. Sargent, Science, 2016, 352, 333.

6 T. Liu, M. Li, C. Jiao, M. Hassan, X. Bo, M. Zhou and H.-L. Wang, J. Mater. Chem. A, 2017, 5, 9377-9390.

7 K. Zhu, T. Wu, Y. Zhu, X. Li, M. Li, R. Lu, J. Wang, X. Zhu and W. Yang, ACS Energy Lett., 2017, 2, 1654-1660.

8 H. Lin, H. Li, Y. Li, J. Liu, X. Wang and L. Wang, J. Mater. Chem. A, 2017, 5, 25410-25419.

9 Y.-Y. Chen, Y. Zhang, X. Zhang, T. Tang, H. Luo, S. Niu, Z.-H. Dai, L.-J. Wan and J.-S. Hu, Adv. Mater., 2017, 29, 1703311.

10 Y. Kuang, G. Feng, P. Li, Y. Bi, Y. Li and X. Sun, Angew. Chem., Int. Ed., 2016, 55, 693-697.

11 J. Wang, L. Li, L. Wang, Y. Liu, W. Sun, W. Li and G. Li, ACS Omega, 2018, 3, 464-471.

12 Z. Lu, M. Sun, T. Xu, Y. Li, W. Xu, Z. Chang, Y. Ding, X. Sun and L. Jiang, Adv. Mater., 2015, 27, 2361-2366.

13 Z. Lu, W. Xu, J. Ma, Y. Li, X. Sun and L. Jiang, Adv. Mater., 2016, 28, 7155-7161.

14 C. Tang, N. Cheng, Z. Pu, W. Xing and X. Sun, Angew. Chem., Int. Ed., 2015, 54, 9351-9355.
15 Q. Zhao, D. Zhong, L. Liu, D. Li, G. Hao and J. Li, J. Mater. Chem. A, 2017, 5, 14639-14645.

16 C. Tang, R. Zhang, W. Lu, Z. Wang, D. Liu, S. Hao, G. Du, A. M. Asiri and X. Sun, Angew. Chem., 2017, 129, 860-864.

17 J. Zhang, T. Wang, P. Liu, Z. Liao, S. Liu, X. Zhuang, M. Chen, E. Zschech and X. Feng, Nat. Commun., 2017, 8, 15437.

18 D. Guo, Y. Luo, X. Yu, Q. Li and T. Wang, Nano Energy, 2014, 8, 174-182.

19 Y. Wu, G.-D. Li, Y. Liu, L. Yang, X. Lian, T. Asefa and X. Zou, Adv. Funct. Mater., 2016, 26, 4839-4847.

20 Y. Rao, Y. Wang, H. Ning, P. Li and M. Wu, ACS Appl. Mater. Interfaces, 2016, 8, 33601-33607.

21 L.-L. Feng, G. Yu, Y. Wu, G.-D. Li, H. Li, Y. Sun, T. Asefa, W. Chen and X. Zou, J. Am. Chem. Soc., 2015, 137, 1402314026.

22 Z. Zhang, Y. Liu, Z. Huang, L. Ren, X. Qi, X. Wei and J. Zhong, Phys. Chem. Chem. Phys., 2015, 17, 20795-20804.

23 Y. Yang, K. Zhang, H. Lin, X. Li, H. C. Chan, L. Yang and Q. Gao, ACS Catal., 2017, 2357-2366.

24 S. Chen, L. Li, W. Hu, X. Huang, Q. Li, Y. Xu, Y. Zuo and G. Li, ACS Appl. Mater. Interfaces, 2015, 7, 22999-23007.

25 Y. Jin, H. Wang, J. Li, X. Yue, Y. Han, P. K. Shen and Y. Cui, Adv. Mater., 2016, 28, 3785-3790.

26 J. Liang, Y.-Z. Wang, C.-C. Wang and S.-Y. Lu, J. Mater. Chem. A, 2016, 4, 9797-9806.

27 J. Meng, J. Fu, X. Yang, M. Wei, S. Liang, H.-Y. Zang, H. Tan, Y. Wang and Y. Li, Inorg. Chem. Front., 2017, 4, 1791-1797.

28 Y. Pi, Q. Shao, P. Wang, F. Lv, S. Guo, J. Guo and X. Huang, Angew. Chem., Int. Ed., 2017, 56, 4502-4506.

29 Y. Wu, Y. Liu, G.-D. Li, X. Zou, X. Lian, D. Wang, L. Sun, T. Asefa and X. Zou, Nano Energy, 2017, 35, 161-170.

30 J. Zhang, T. Wang, D. Pohl, B. Rellinghaus, R. Dong, S. Liu, X. Zhuang and X. Feng, Angew. Chem., Int. Ed., 2016, 55, 6702-6707.

31 L. Fang, W. Li, Y. Guan, Y. Feng, H. Zhang, S. Wang and Y. Wang, Adv. Funct. Mater., 2017, 27, 1701008.

32 S. Wan, J. Qi, W. Zhang, W. Wang, S. Zhang, K. Liu, H. Zheng, J. Sun, S. Wang and R. Cao, Adv. Mater., 2017, 29, 1700286.

33 J. Li, W. Xu, D. Zhou, J. Luo, D. Zhang, P. Xu, L. Wei and D. Yuan, J. Mater. Sci., 2018, 53, 2077-2086.

34 X. Zhao, X. Shang, Y. Quan, B. Dong, G.-Q. Han, X. Li, Y.-R. Liu, Q. Chen, Y.-M. Chai and C.-G. Liu, Electrochim. Acta, 2017, 230, 151-159. 